\title{
Fault Tests for Cable Core
}

This content has been downloaded from IOPscience. Please scroll down to see the full text. 1899 Proc. Phys. Soc. London 17104

(http://iopscience.iop.org/1478-7814/17/1/309)

View the table of contents for this issue, or go to the journal homepage for more

Download details:

IP Address: 130.237.122.245

This content was downloaded on 09/09/2015 at 05:21

Please note that terms and conditions apply. 


\section{Fault Tests for Cable Core. By Rollo Appleyard.*}

THE following method of localizing faults has been found especially useful for braided core, and for core protected by ozokerited-tape. It does not require these coverings to be removed or cut. Fig. 1 shows a convenient arrangement of the test. Drums $A$ and $B$ are supported upon ebonite bearings. The electrical connexions are those of the "direct deflexion" method, with the addition of a wire, CD, called

Fig. 1.

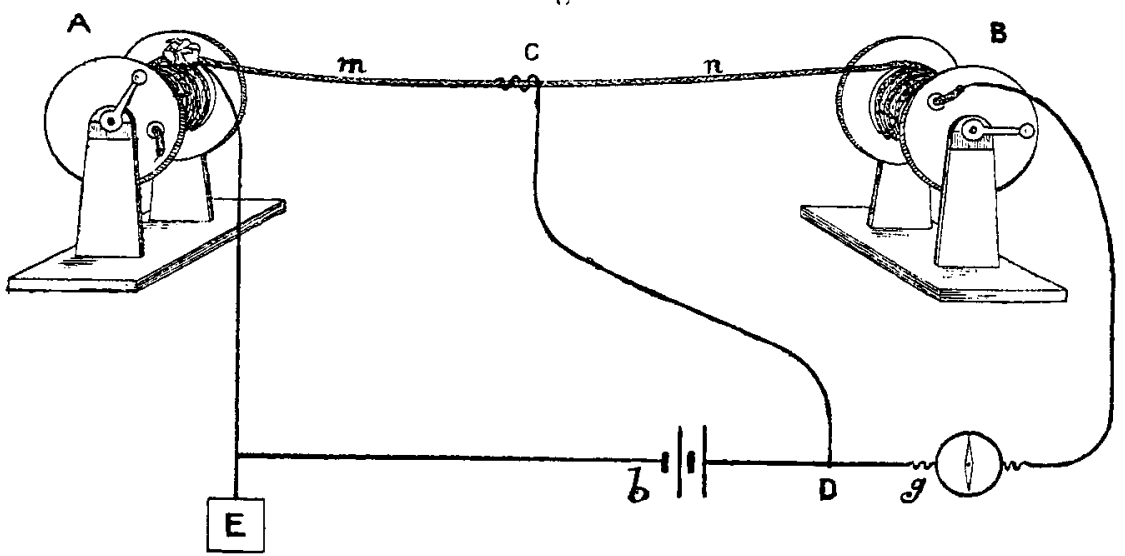

the "guard-wire." The guard-wire terminates at $\mathrm{C}$ in a rubbing-contact piece, which may be a metallic brush or a wet sponge. The ends of the core are brought out through the flanges of the drums. For the sake of clearness, the ends in fig. 1 are shown connected directly to the testing circuit; in practice each end of the conductor should be connected to the iron axle of its corresponding drum. Contact with the testing-circuit can then be made through the brass bushing of the ebonite bearing of drum B. A wet cloth attached to an an earth-wire, shown on drum $A$, can be placed either upon A or B. In the case of bare core it is convenient to cover the whole length from $A$ to $B$ with damp cloth.

* Read January 26, 1900. 
Faults in core may be (1) single, (2) multiple, or (3) distributed. They may vary in resistance from zero to comparatively high values. It is probable that for each class of fault there is a particular method best suited for determining its position. But whatever the nature of the fault, the guard-wire will be found a most useful aid to localization.

(1) When a single fault of low resistance passes through the contact at $\mathrm{C}$, its presence is indicated by a sudden fall in the deflection, for the galvanometer is at that moment automatically short-circuited through the conductor of the cable. Note that the galvanometer is thus completely protected. Simultaneously the battery is connected directly to the fault, and generally burns it out.

(2) A fault thus localized should be removed, by cutting it away from the dielectric, and temporarily repaired. The core can then be carried on through $\mathrm{C}$. If there are several faults, the deflexion will fall as each in succession passes the guard-wire.

(3) In the case of faults distributed along several inches, or even yards, of the core, the bad portion can always be hrought to the intermediate stretch from $A$ to $B$. For this purpose, the earth-cloth should first be laid upon $A$, and the deflexion noted; it should then be removed to $B$, and the corresponding deflexion observed. This determines whether the faulty portion is upon $\mathrm{A}$ or upon $\mathrm{B}$, and by winding core from the faulty drum to the good drum, in measured lengtbs, and by comparing corresponding successive pairs of deflexions, the faulty portion passes ultimately from one drum to the other. If the faulty portion is in this way located somowhere along the stretch between $\mathrm{C}$ and $\mathrm{B}$, it is clear that by moving the guard-wire from $\mathrm{C}$ towards $\mathrm{B}$ the deflexion will gradually diminish, for the current through the galvanometer is thereby more and more shunted. If the fault is uniformly distributed, the fall of deflexion is approximately proportional to the distance thus traversed by $C$. The rate at which it falls as $\mathrm{C}$ moves towards $\mathrm{B}$ can be compared with the rate of falling when good core is substituted for the faulty portion, between $\mathrm{C}$ and $\mathrm{B}$. 


\section{Appendix.}

Qualitative 'tests are, as a rule, sufficient for localizing faults in such lengths of core as can be handled in this convenient way. Some interest, however, attaches to the quantities involved, especially as the equations happen to be applicable to nearly all cases arising from the use of a guard-wire.

In a paper read before the Physical Society in May 1896,* upon "Dielectrics," certain tests by the "direct deflexion" method were described, in which the "guard-wire," suggested by $\mathrm{Mr}$. W. A. Price, was used to prevent end-leakage. For this purpose the guard-wire was applied so as to intercept the path of leakage at the "end" of the core. It was therefore placed at a point about halfway along the cleaned "end," thus leaving about three inches of cleaned dielectric on each side of it. In the present use of the guard-wire for localizing faults, it may be supposed removed from the "ends" and applied to the braiding at some point of the stretch of core intermediate between the drums, as at $\mathrm{C}$ in fig. 1 . The core may be braided or taped, and it may be wet, without prejudice to this method of localizing faults. Let the total surface-resistance between $\mathrm{A}$ and $\mathrm{B}$ be $m+n$ ohms, intercepted by the guard-wire at $\mathrm{C}$ between $m$ and $n$. The "ends" need not be cleaned; and we may suppose the core, including that on the drums, to be thuroughly wet. The resistance $m$, in effect, shunts the battery; similarly $n$ shunts the galvanometer. Also let $r$ be the ordinary "dielectric resistance" of the total length of core when there is no fault; $f$ the resistance of the fault; $b$ the battery resistance; $g$ the resistance of the galvanometer; and $\mathrm{E}$ the E.M.F. of the battery. Then, so far as it is permissible to apply Kirchhoff's laws to such "resistances," $\dagger$ the current G through the galvanometer is given by :

$$
\begin{aligned}
\mathrm{G}= & \frac{\mathrm{E}}{(r+g+b)+\left[\frac{g}{m}(r+b)+\frac{b}{n}(r+g)+\frac{b r g}{m n}\right] .} \\
& \text { * Proc. Phys. Soc. vol xjv. p. 255. } \\
& + \text { 'Electrician,' July 24th, 1896, p. 403. }
\end{aligned}
$$


If the fault is on the $\mathrm{A}$ side of $\mathrm{C}$, it is necessary to substitute $\frac{m f}{m+f}$ for $m$. If the fault is on the B side, $\frac{n f}{n+f}$ should be substituted for $n$. By evaluating the above expression for $G$, almost any case can be examined, either for the purposes of the present test, or for any application of the guard-wire. The best way to determine the magnitude of possible errors is first to evaluate the quantity included between the square brackets, and then to compare this with $(r+g+b)$.

\section{The Frequency of Transverse Vibrations of a Stretched} Indiarullier Cord. By T. J. BAK ER, B.Sc.*

TeE writer has observed that the pitch of the note produced by twanging an indiarubber band which is stretehed over the fingers is infuenced but little by the tension, particularly if this is considerable.

'The matter appeared worthy of further investigation; and for this purpose a short piece of indiarubber cord, of square section, was attached at one end to the midule of a tambourinediaphragm, while the other end was bound to a piece of twine which passed over a pulley-wheel and supported a weighed stale-pan.

After placing a weight in the pan, the rubber was allowed to stretch for some minutes, and then the end nearest the pan was firmly clamped. The intensity of the note produced by transverse vibrations of the cord was rendered sufficiently great by the tambourine to permit a determination of pitch by comparison with a sonometer and tuningfork.

The sectional area of the cord under the various tensions employed was determined by measurements of its two diameters at three different points in its length.

For this purpose a micrometer-gange reading to $\cdot 001 \mathrm{~cm}$. was employed. The observations were continued until the

* Read January 26, 1900. (Communicated by Prof. Poynting.) 